بررسى تاثير عوامل زمين محيطى بر شكل

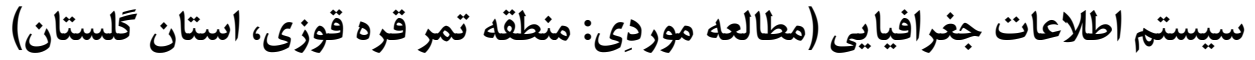

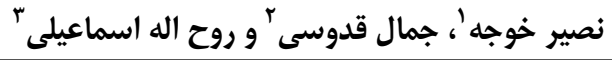

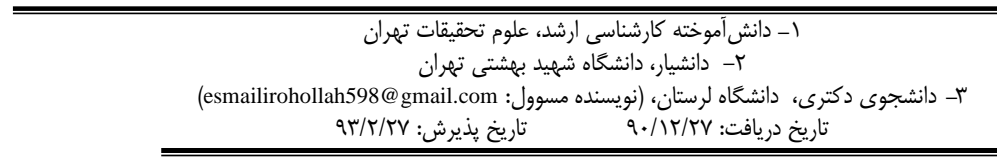

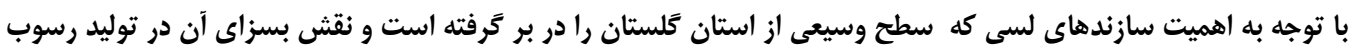

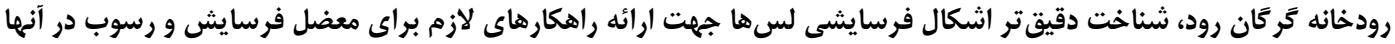

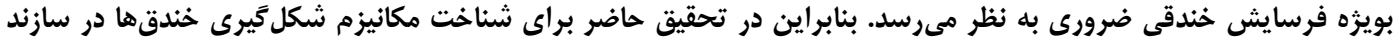

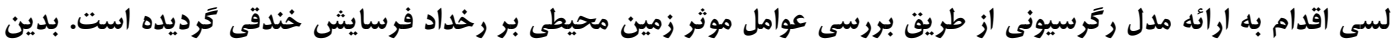

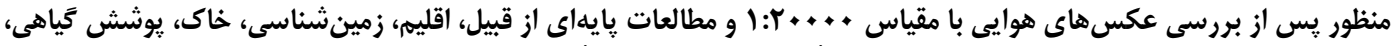

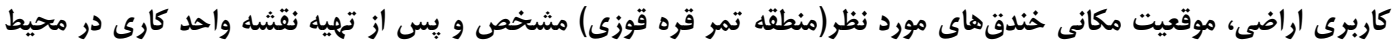

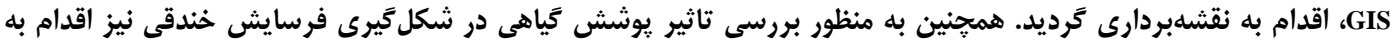

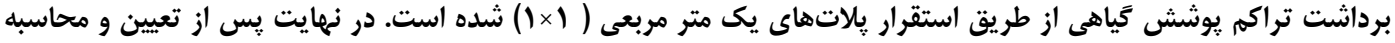

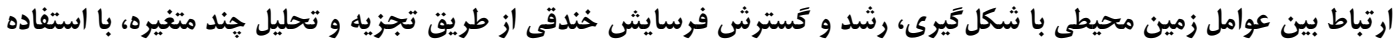

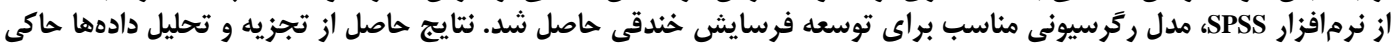

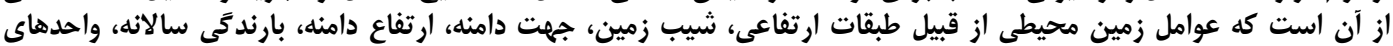

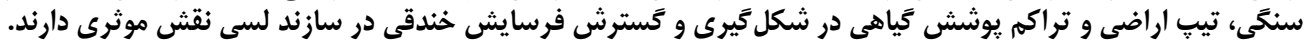

وازمهاى كليدى: فرسايش خندقى، لس، مكانيسم شكلَّيرى خندق، عوامل زمين محيطى، مدل رتر سيونى، GIS

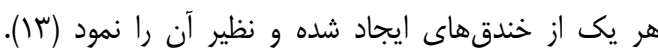

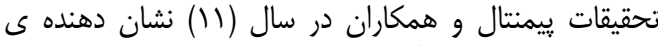

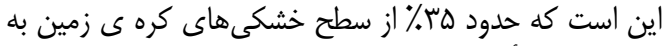

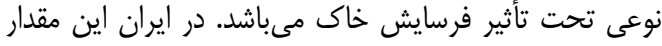

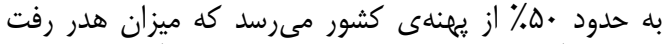

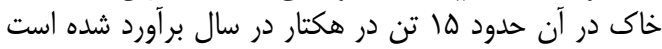

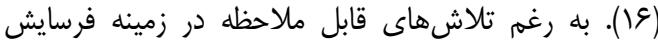

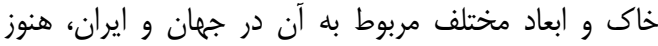

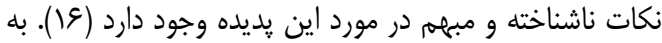

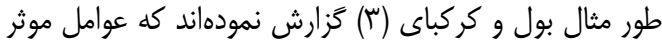

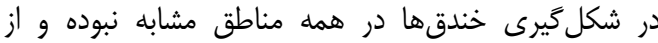

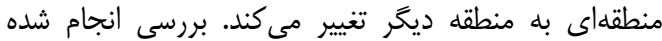

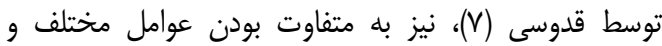

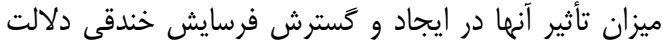

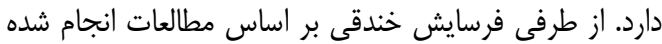

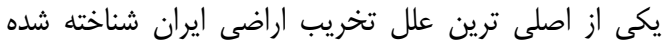

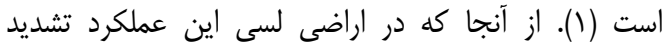

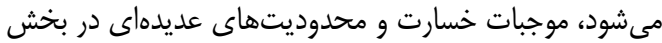

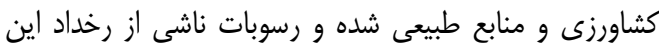

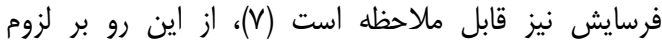

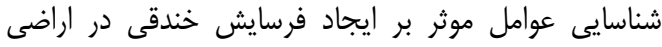

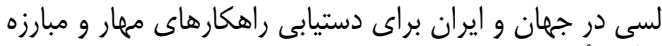

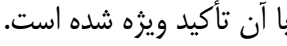

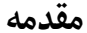

ييامدهاى فرسايش خاك توسط برخى از يزوهشكَران به

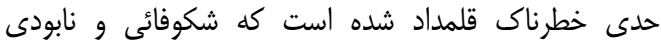

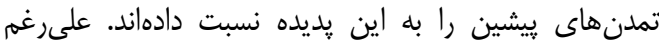

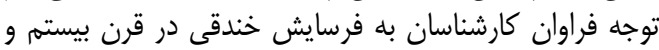

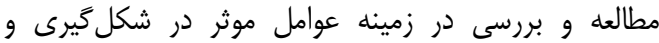

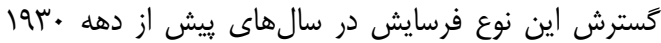

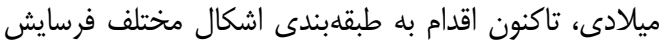

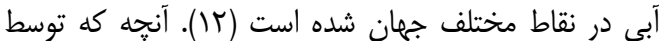

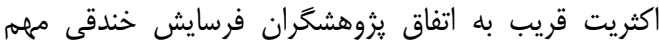

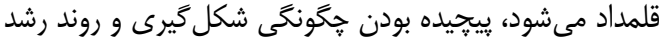

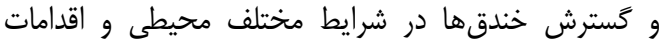

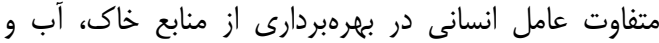

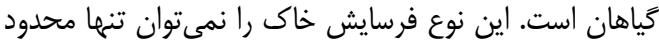

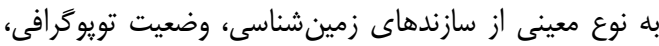

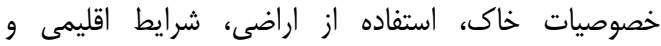

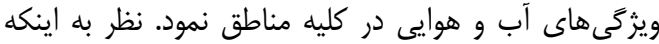

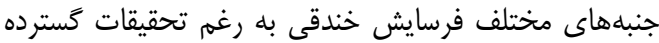

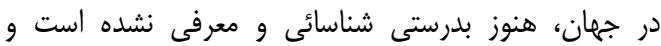

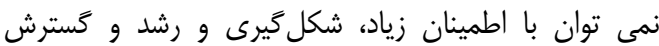

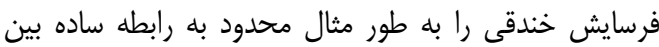

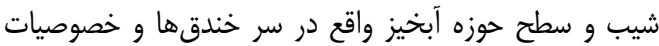

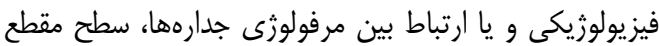
و شيب خندقها با ساير خصوصيات فيزيكى حوزههاى آبخيز 
عوامل تأثير كذار مىباشد كه لازم است شناسايى كردند (IF.IF_T)

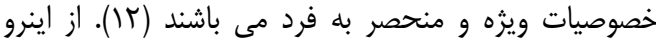

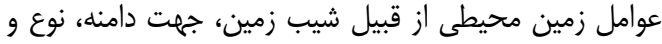

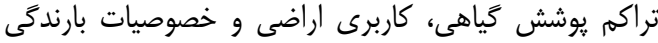
نقش اساسى را مىتوانند در رخداد بيدايش فرائ فرسايش خندقى باري

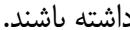

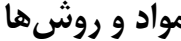
منطقه مورد مطالعه

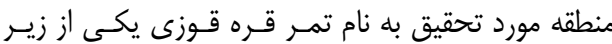

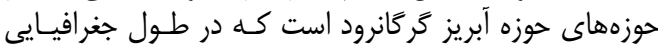
ك ه ه ه DVار در شمال شرق شهرستان

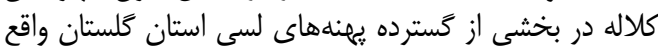

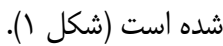

با توجه به كَتره مناطق لسى در ايران در استانهاى

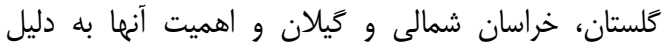
حاصلخيزى در بخش كشاورزى و وبه لحاظ وجان وجود كانى الهاى

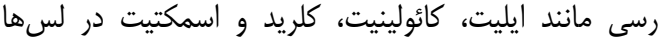

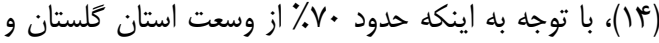

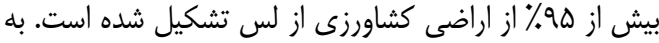

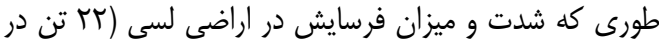

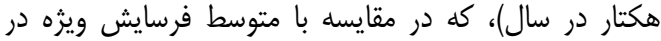

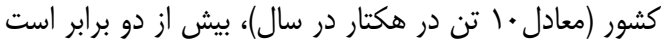
(V)

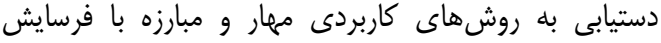

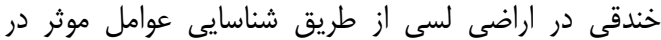

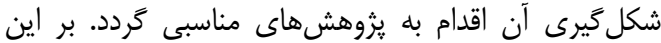

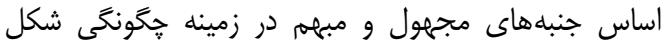

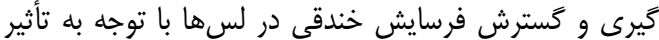

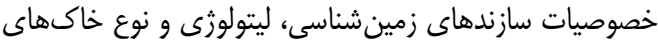

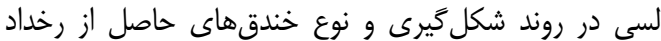

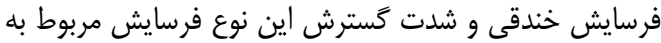

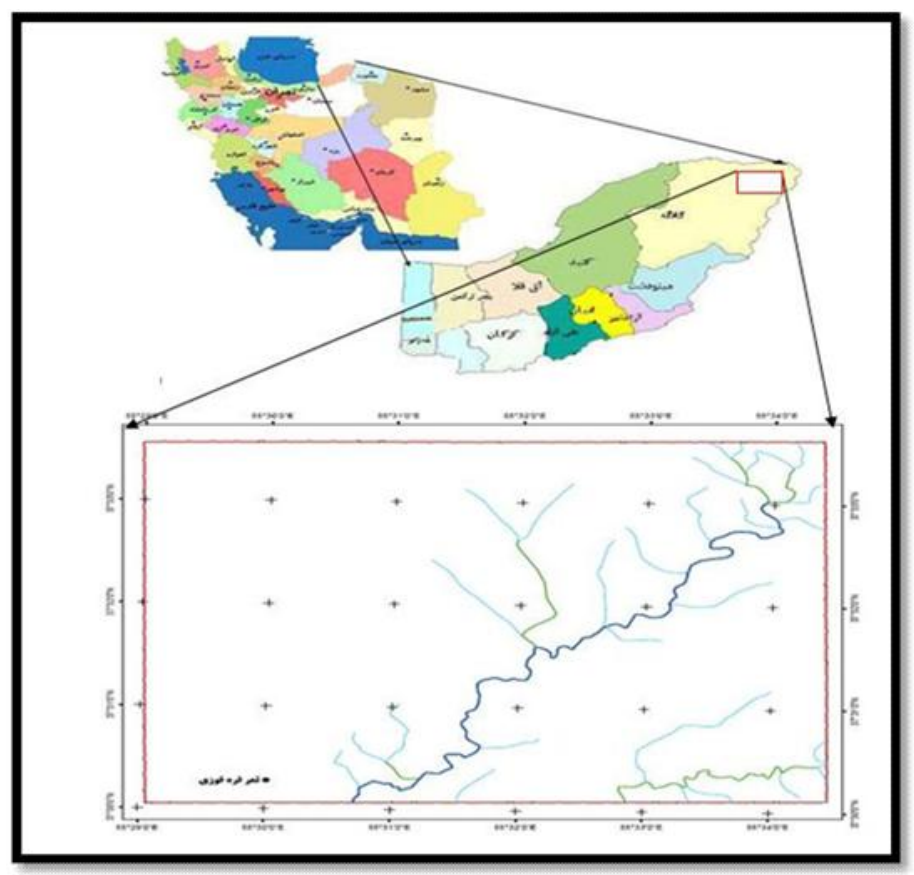

شكل 1- موقعيت مكانى منطقه مورد مطالعه در ايران و استان كلستان

Figure 1. The location of study area within Iran, Golestan province

تقسيمات زمينشناسى ايران، اين منطقه از لس بسيار ضـخيم تشكيل شده است.

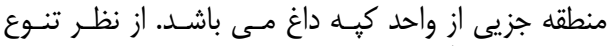

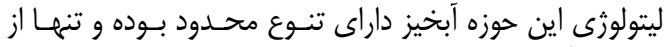

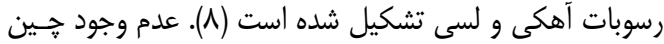

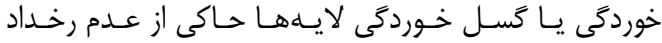

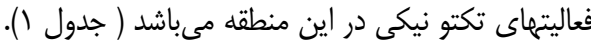

منطقه مورد مطالعه شيب متوسط Dاه ه درصد، داراى

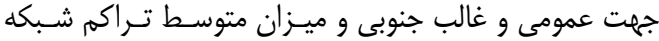

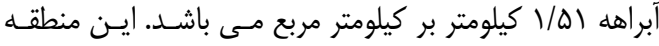

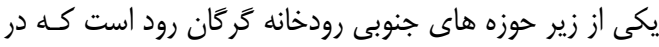

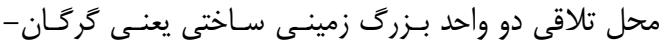

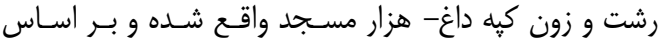



بررسى تاثير عوامل زمين محيطى بر شكل گيرى و كَترش فرسايش خندقى با استفاده از سيسته اطلاعات جغرافيايى.

Table 1. Geological characteristics of the study area

جدول ا- خصوصيات زمينشناسى منطقه مورد مطالعه

\begin{tabular}{|c|c|c|c|c|c|c|}
\hline فراوانى نسبى (درصد) & مساحت (هكتار) & ليتولوزى & علامت & زمان & سازند زمينشناسى & رديف \\
\hline $11 / 19$ & DVq & سليت - ماسه ، شن & Qal & 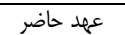 & آبرفت عهد حاضر & 1 \\
\hline$\wedge \&|\wedge|$ & FAM & لس شامل سليت، ماسه و مقدارى شن & QL & كواترنر & لس & r \\
\hline $1 / 99$ & $1 . \mu$ & شيل سياه حاوى كنخَر سيون رسى آهن دار & KS & كر تاسه زيرين & سنكانه & r \\
\hline
\end{tabular}

هواييى مربوط به سالهـاى هسبا و عبسا همـراه بـا تصـوير

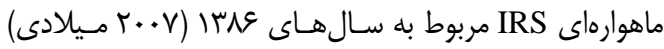

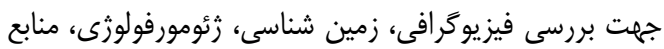

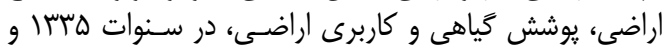

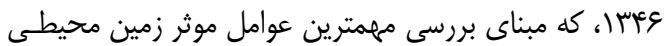

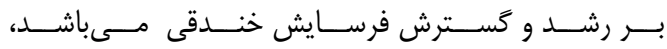

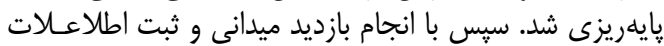

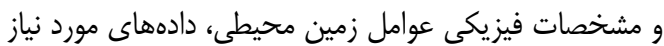

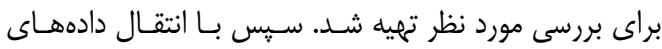

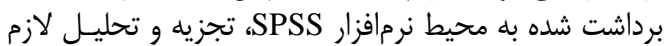

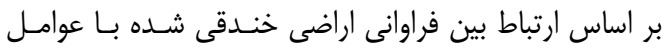

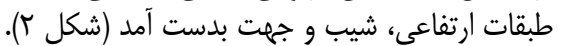

دادههاى مورد استفاده:

در انجام اين تحقيق به ترتيب از مواد زيتفاده: استفاده شده است:

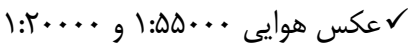

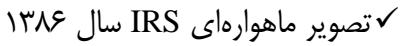
لوبسته نرمافزار

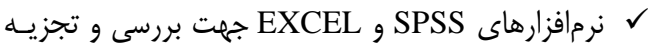

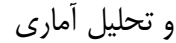
روش تحقيق:

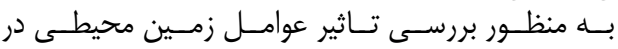

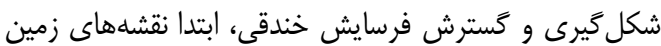

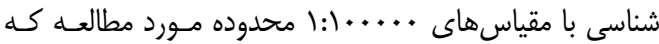

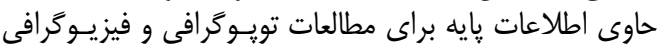

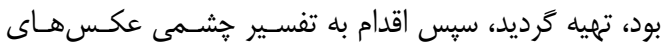

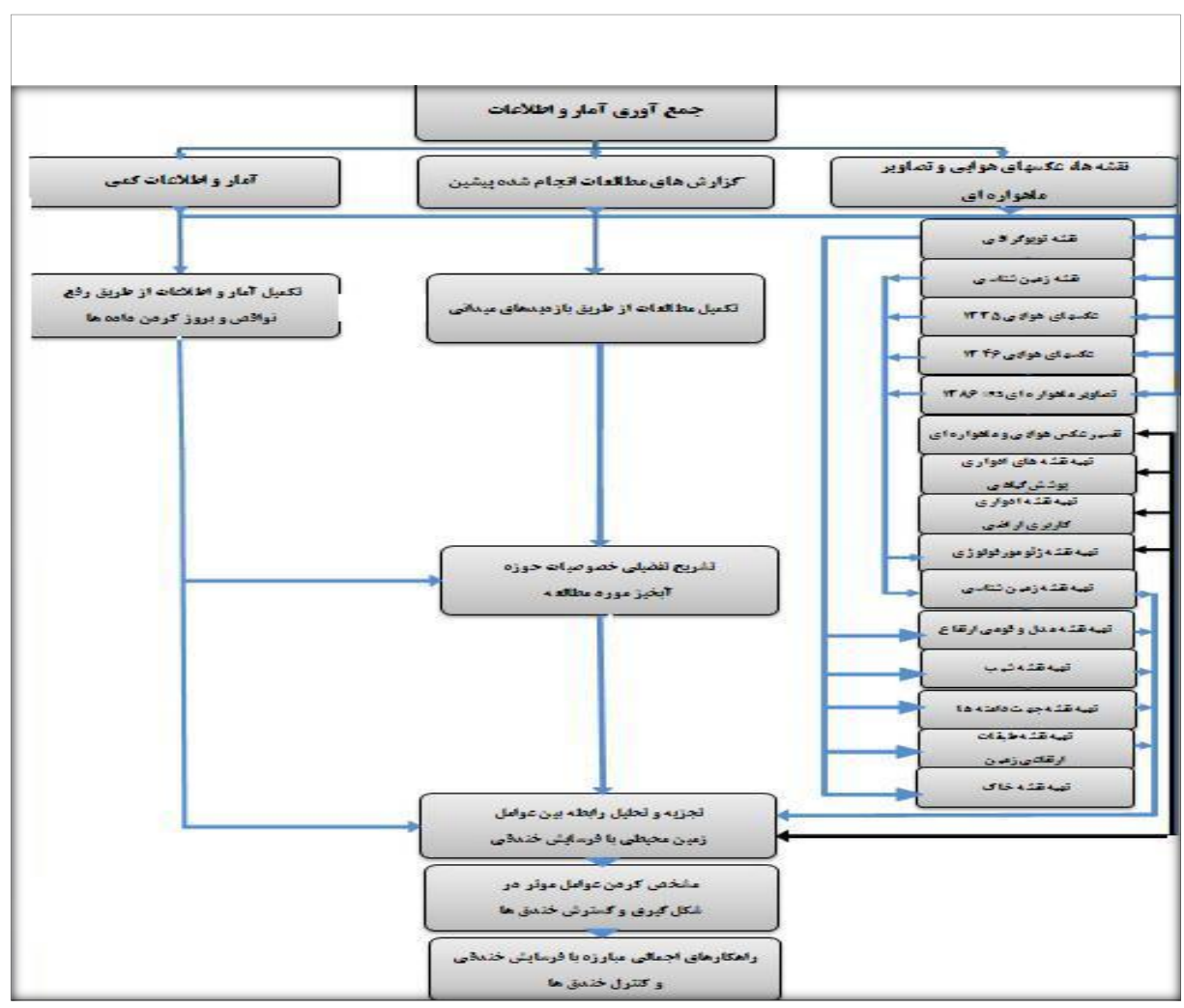

شكل r- روند نمايى انجام مراحل تحقيق

Figure 2. Exponential trend of research Process 


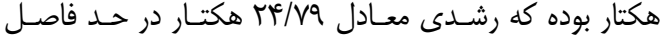

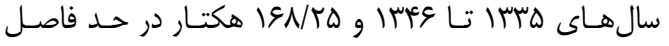

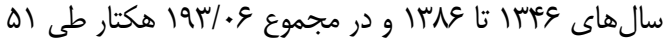

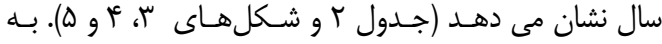

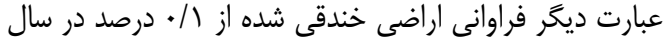

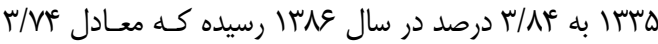
درصد رشد داشته است.

\section{نتايج و بحث توجن}

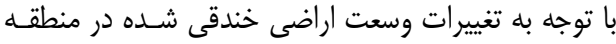

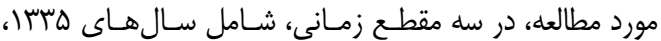

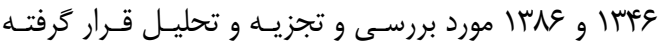

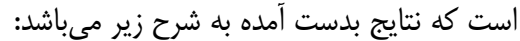
تغييرات اراضى خندقى به تفكيك مقاطع زمانى ارنى

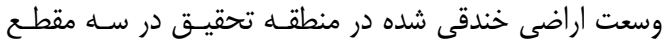

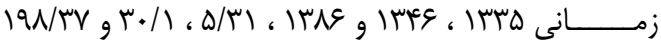

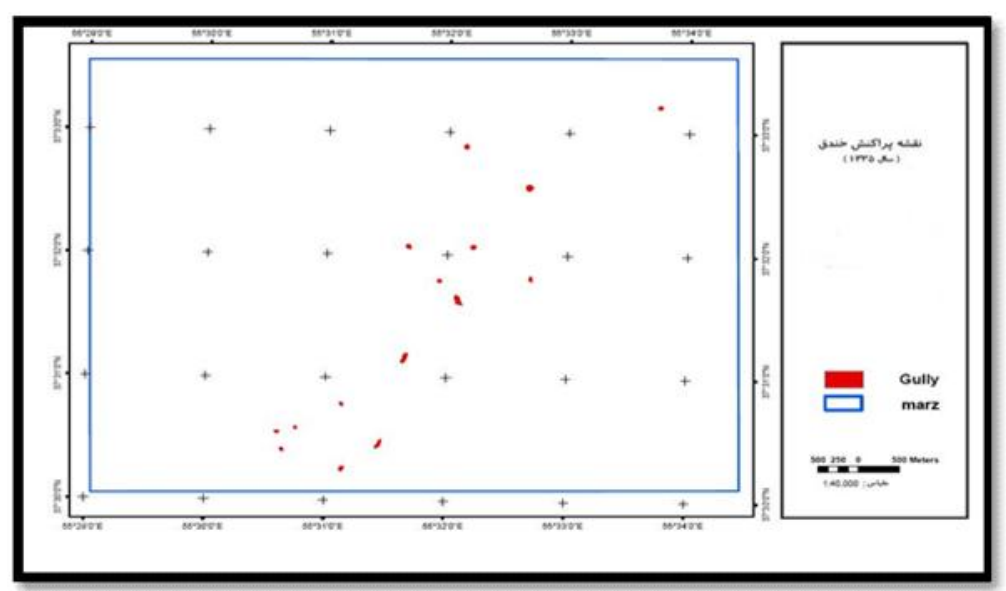

شكل ץ- نقشه يراكنش مكانى مناطق خندقى شده در سال هـrا

Figure 3. the spatial distribution of gullies in 1335

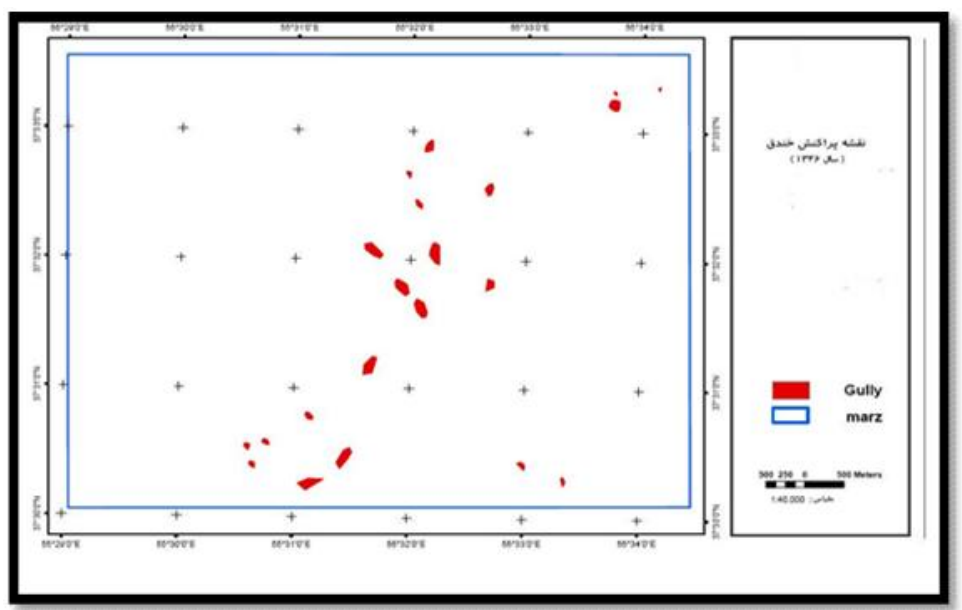

شكل عـ- نقشه يراكنش مكانى مناطق خندقى شده در سال عابرا

Figure 4. the spatial distribution of gullies in 1346 


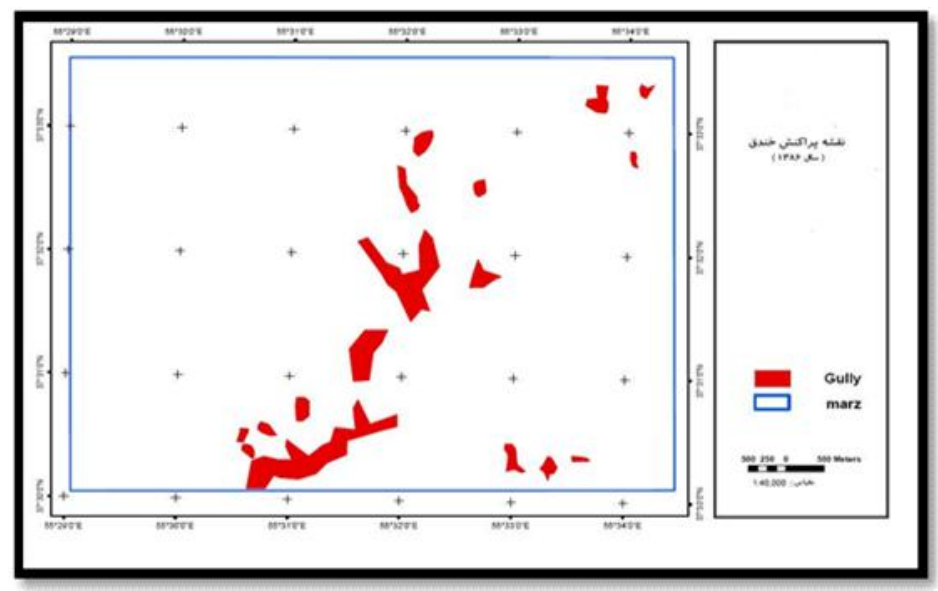

شكل ه- نقشه يراكنش مكانى مناطق خندقى شده در سال عNس|

Figure 5. the spatial distribution of gullies in 1386

جدول r- تغييرات وسعت و فراوانى اراضى خندقى شده در مقاطع زمانى مورد مطالعه

Table 2. Changes of size and frequency of gully area in the time periods studied

\begin{tabular}{|c|c|c|c|}
\hline IrNe & ITES & ITHa & سال \\
\hline $19 \mathrm{~N} / \mathrm{TV}$ & $r \cdot / r$ & $\Delta / \mu^{\prime}$ & وسعت اراضى خندق شده (هكتار) \\
\hline$r / \lambda \mu$ & $\cdot / \Delta \Lambda$ &.$/ 1$ & ميزان ت تغييرات (درصد) \\
\hline
\end{tabular}

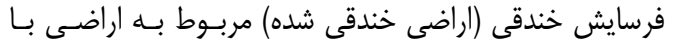

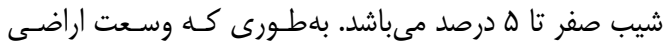

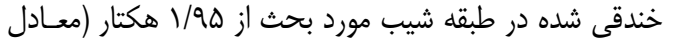

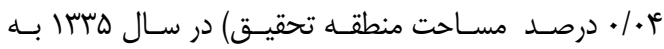

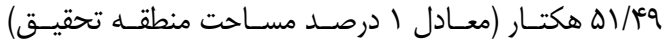
افزايش داشته است.

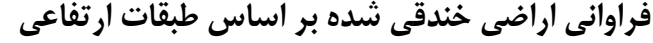

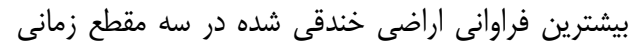

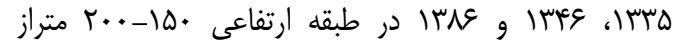

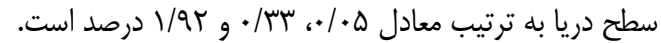

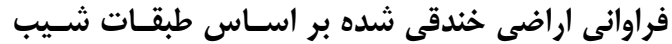
زمين

در منطقه مورد مطالعه بيشترين فراوانى رخداد و گَسترش

جدول ب- تغييرات وسعت و فراوانى اراضى خندقى شده بر اساس طبقات ارتفاعى در مقاطع زمانى مورد مطالعه Table 3. Changes of size and frequency of gully area based on elevation at the time periods studied

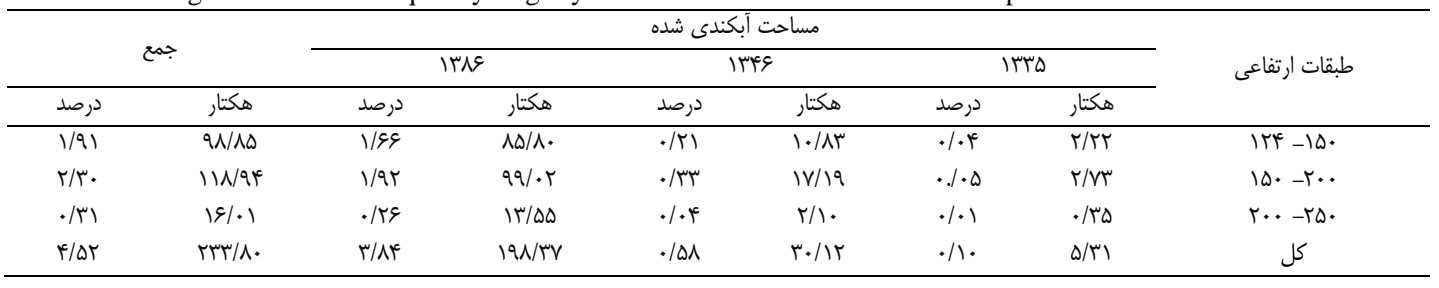

جدول عأ- تغييرات وسعت و فراوانى اراضى خندقى شده بر اساس طبقات شيب زمين در مقاطع زمانى مورد مطالعه Table 4. Changes of size and frequency of gully area based on slope classes at the time periods studied

\begin{tabular}{|c|c|c|c|c|c|c|c|c|}
\hline \multirow{2}{*}{\multicolumn{2}{|c|}{ جمع }} & \multicolumn{6}{|c|}{ مساحت أبكندى شده } & \multirow{3}{*}{ طبقات شيب } \\
\hline & & \multicolumn{2}{|c|}{ IrNe } & \multicolumn{2}{|c|}{ ITES } & \multicolumn{2}{|c|}{ DTHו } & \\
\hline مرصد & هكتار & درصد & هكتار & درصد & هكتار & درصد & هكتار & \\
\hline I/TY & gr/TV & $1 / \cdots$ & $01 / 4 q$ &.$/ 19$ & Q/AT & $\cdot 1 \cdot t^{4}$ & $1 / 9 \Delta$ & $\cdot-\phi$ \\
\hline • & ET/V. & . & TV/qD & $\cdot / \cdot 1$ & F/Ta & $.1 \cdot 1$ &.$/ 49$ & $\Delta-1$. \\
\hline$\cdot / \mathrm{VA}$ & $f \cdot / f$. & $.19 \mathrm{~V}$ & TY/DT & .1 .9 & f/Af &.$/ \cdot 4$ & $1 / \cdot t^{2}$ & 1. -4 . \\
\hline$\cdot / \mu \cdot$ & $|\Delta / f|$ & $\cdot / T V$ & $1 \pi / M$ & . & 1/Dr & $\cdot / \cdot$ & $\cdot 1+$ & $r \cdot r \cdot$ \\
\hline .190 & $m / F \Delta$ & . $/ \Delta T$ & $r V / \cdot D$ &.$/ 11$ & $\Delta / \Delta)$ & $\cdot / r$ &.$/ 9$. & $r \cdot-r$. \\
\hline$\cdot / V Q$ & 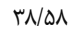 & $\cdot / 8 \Delta$ & m & $\cdot 1 \cdot 1$ & $F / \cdot V$ & .1 .4 & $d \cdot r$ & $>f$. \\
\hline F/QT & (ג/אזr. & r/Af & $191 / \mathrm{rV}$ & $\cdot / \Delta \Lambda$ & r./K &.$/ 1$ & D/T & كل \\
\hline
\end{tabular}




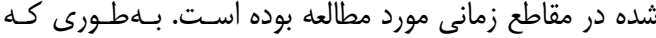

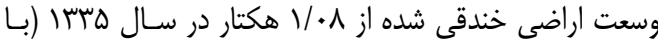

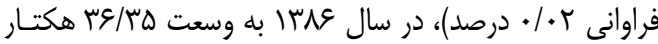

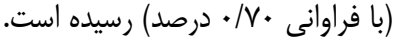

فراوانى اراضى خندقى بـر اســاس جهــت دامنـههــاى

شيبدار

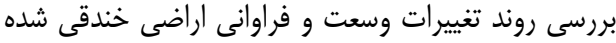

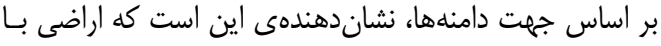

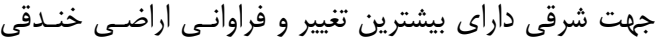

جدول ه- تغييرات وسعت و فراوانى اراضى خندقى شده بر اساس جهت دامنه ها در مقاطع زمانى مورد مطالعه Table 5. Changes of size and frequency of gully area based on aspect at the time periods studied

\begin{tabular}{|c|c|c|c|c|c|c|c|c|}
\hline \multirow{2}{*}{\multicolumn{2}{|c|}{ جمع }} & \multicolumn{6}{|c|}{ مساحت آبكندى شده } & \multirow{3}{*}{ جغرافيايى } \\
\hline & & \multicolumn{2}{|c|}{ (TNE } & \multicolumn{2}{|c|}{ IHES } & \multicolumn{2}{|c|}{ פנזו } & \\
\hline درصد & هكتار & مرصد & هكتار & درصد & هكتار & ل درصد & هكتار & \\
\hline$\cdot / H V$ & $19 / \cdot \Delta$ &.$/ 49$ & $10 / 19$ & .1 .9 & 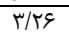 & $.1 \cdot 1$ &.$|8|$ & $\mathrm{N}$ \\
\hline س4א/. & $r T / F Q$ & 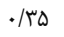 & $11 / 19$ & $\cdot / \cdot v$ & r/VT & $.1 \cdot 1$ & $\cdot / \Delta F^{C}$ & NE \\
\hline$\cdot / \Lambda \Delta$ & $F+1 \cdot \Delta$ & $\cdot / \mathrm{V}$ & هץ/ع & سו/. & glar & $\cdot / \cdot r$ & $1 / \cdot 1$ & $\mathrm{E}$ \\
\hline$\cdot / V$ & 海/Tr & $\cdot / \& \Delta$ & 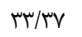 & $\cdot / \cdot \Delta$ & $T / \Delta \Delta$ & $.1 \cdot 1$ & ه & S E \\
\hline$\cdot / 4 F$ & Tr/VD & ع שא/. & $\mid N / F \Delta$ & $\cdot / \cdot v$ & $\Gamma / \Delta \Lambda$ & $.1 \cdot 1$ & $\cdot / V T$ & $S$ \\
\hline$\cdot / D V$ & $r q / r$. & $\cdot / F V$ & TH/Tr & $\cdot 1 \cdot 1$ & $r / r q$ &.$/ \cdot 1$ & .199 & S W \\
\hline س4/א & $r T / \cdot D$ & 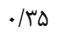 & N/T. & .1 .9 & $r / 9 \Lambda$ &.$/ \cdot r$ & $\cdot / \wedge \vee$ & W \\
\hline$\cdot / V r$ & $r V / M$ & .198 & $m \in / T$. & .1 .9 & m &.$/ \cdot 1$ & $\cdot / \& \Delta$ & N W \\
\hline F/ar & ( & r/入ץ & $191 / \mathrm{rV}$ &.$/ \Delta \Lambda$ & $r \cdot / 1 t$ &.$/ 1$ & 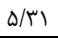 & كل \\
\hline
\end{tabular}

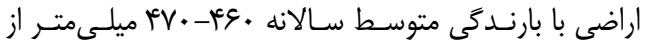

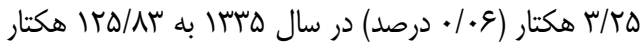

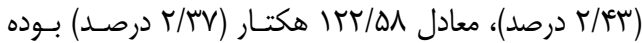

\section{فراوانى اراضى خنــدقى بــر اســاس متوسـط مقــدار بارند

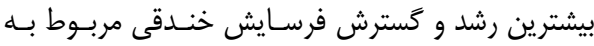

جدول צ- تغييرات وسعت و فراوانى اراضى خندقى شده بر اساس متوسط ارتفاع بارندگى در مقاطع زمانى مورد مطالعه Table 6. Changes in size and frequency of gully area based on the average of rainfall in the time period studied

\begin{tabular}{|c|c|c|c|c|c|c|c|c|}
\hline \multirow{2}{*}{\multicolumn{2}{|c|}{ جمع }} & \multicolumn{6}{|c|}{ مساحت آبكندى شده } & \multirow{3}{*}{ (ميلى بارندىى) } \\
\hline & & \multicolumn{2}{|c|}{ IH人 } & \multicolumn{2}{|c|}{ Irfes } & \multicolumn{2}{|c|}{ (משו } & \\
\hline درصد & هكتار & درصد & هكتار & درصد & هكتار & درصد & هكتار & \\
\hline $1 / \mp \Delta$ & $V \Delta / \cdot V$ & $1 / 19$ & $09 / 9 F$ & $\cdot / T \Delta$ & $\mid r / \cdot V$ & $\cdot / \cdot f^{f}$ & $4 / \cdot S$ & $+\theta \cdot-19$. \\
\hline$r / \Lambda)$ & $\| F \Delta / / T$ & $r / 4 T$ & $\mid r \Delta / \Lambda T$ & • & $|q| \cdot f$ & .1 .9 & $\Gamma / T \Delta$ & $p \varepsilon \cdot-p V$. \\
\hline س r./. & $1 / \Delta H$ & $\cdot / \cdot r$ & $1 / \Delta H$ & $\cdot 1 \cdot$ & 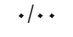 & $\cdot / \cdot$ & $\cdot 1 \cdot \cdot$ & $r v \cdot-r \lambda$. \\
\hline - & $11 / 48$ & $\cdot / \pi$ & $1 \cdot / \mathbb{F} \Delta$ &.$/ \cdot t$ & $1 / \cdot 1$ & $\cdot / \cdot$ & $.1+$ & rᄉ. $-r q$. \\
\hline $.1 \cdot 1$ & سצ|. &.$/ \cdot 1$ & س &.$/$. &. &.$/$. &.$/$. & $p q \cdot-\phi \cdots$ \\
\hline$F / \Delta T$ & (1/ . & r/AF & $191 / \mathrm{TV}$ & $\cdot / \Delta \Lambda$ & $r \cdot / 1 r$ & $\cdot / 1$ & ه/TI & 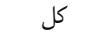 \\
\hline
\end{tabular}

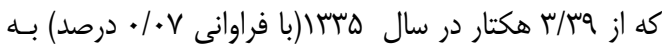
كه

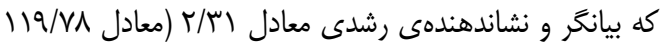
هكتار) مىباشد.
فراوانى اراضى خندقى بر اساس واحدهاى سنكَى

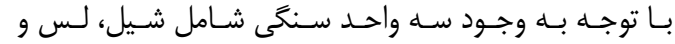

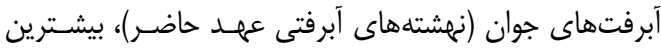

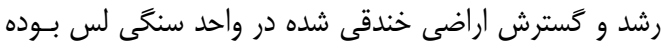

جدول V- تغييرات وسعت و فراوانى اراضى خندقى شده بر اساس واحدهاى سنكى در مقاطع زمانى مورد مطالعه Table 7. Changes in the size and frequency of gully area based on lithological unites in the time period studied

\begin{tabular}{|c|c|c|c|c|c|c|c|c|}
\hline \multirow{2}{*}{\multicolumn{2}{|c|}{ جمع }} & \multicolumn{6}{|c|}{ مساحت آبكندى شده } & \multirow{3}{*}{ سازند زمين شناسى } \\
\hline & & \multicolumn{2}{|c|}{ IrNE } & \multicolumn{2}{|c|}{ Irks } & \multicolumn{2}{|c|}{ פחוז } & \\
\hline درصد & هكتار & درصد & هكتار & درصد & هكتار & درصد & هكتار & \\
\hline.$/ 1 Q$ & $\mathrm{~V} / \mathrm{M}$ &.$/ 1 f$ & $V / \& \wedge$ & $.1 \cdot 1$ & $\cdot / 4$ &.$/$. &.$/$. & شيل \\
\hline$r / \Lambda \Delta$ & $I F V / I V$ & $r / \mu$ & IT/IV & $\cdot / 4$ & $r \cdot / g t$ & $\cdot 1 \cdot v$ & 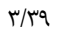 & 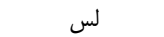 \\
\hline V/QT & $V N / V \Delta$ & $1 / \mu$ & $g V / V Y$ &.$/ 11$ & १/।. & $.1 . \mathrm{f}$ & $1 / 94$ & آبرفتهاى جوان \\
\hline r/ar & . & r/Af & $191 / \% V$ & $\cdot / \Delta \Lambda$ & $r \cdot / r$ &.$/ 1$ & 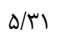 & كل \\
\hline
\end{tabular}




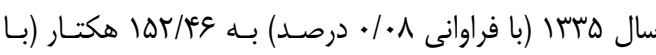

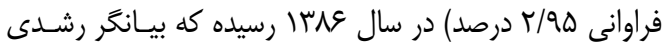

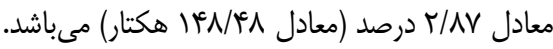

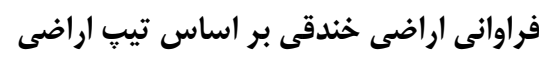

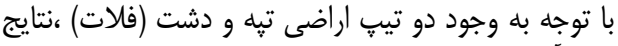

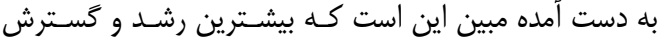

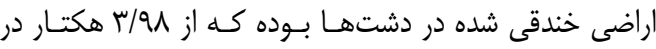

جدول ^- تغييرات وسعت و فراوانى اراضى خندقى شده بر اساس تيب اراضى در مقاطع زمانى مورد مطالعه Table 8. Changes in the size and frequency of gully area based on land types in the time period studied

\begin{tabular}{|c|c|c|c|c|c|c|c|c|}
\hline \multirow{2}{*}{\multicolumn{2}{|c|}{ جمع }} & \multicolumn{6}{|c|}{ مساحت آبكندى شده } & \multirow{3}{*}{ نيّ اراضى } \\
\hline & & \multicolumn{2}{|c|}{ IHNE } & \multicolumn{2}{|c|}{ Irts } & \multicolumn{2}{|c|}{ IMTD } & \\
\hline درصد & هكتار & درصد & هكتار & درصد & هكتار & درصد & هكتار & \\
\hline .199 & $m+/ . q$ & $\cdot / \Delta \mathrm{V}$ & $4 q / 4)$ & $\cdot 1 \cdot 1$ & r/^9 &.$/ .4$ & $\cdot / \mathrm{VA}$ & تيه \\
\hline$r / \mathcal{E V}$ & IVQ/DT & $r / 9 \Delta$ & IDT/FE & $\cdot / \& \Delta$ & 1\%ץ & $\cdot / \cdot 1$ & r/qu & دشت \\
\hline ./49 & $r \cdot / 19$ & ז'ון & $18 / 49$ & .1 .9 & $\Gamma / 1 Q$ &.$/ \cdot 1$ & $\cdot / \Delta F$ & تراس رودخانهاى \\
\hline F/OT & . & r/Af & $191 / r V$ & $\cdot / \Delta \Lambda$ & $r \cdot / 1 t$ & $\cdot / 1$ & D/T & 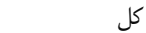 \\
\hline
\end{tabular}

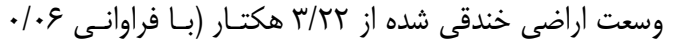

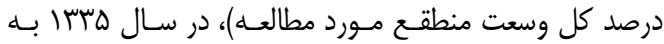

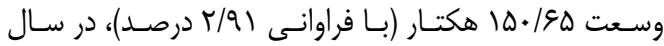

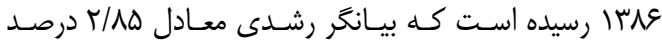

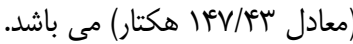

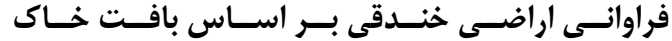

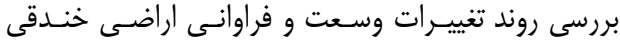

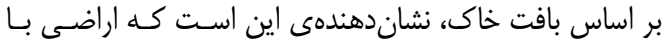

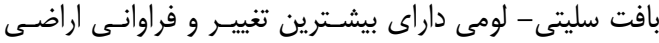

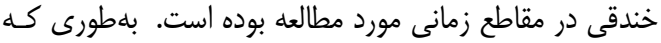

جدول q- تغييرات وسعت و فراوانى اراضى خندقى شده بر اساس بافت خاك در مقاطع زمانى مورد مطالعه Table 9. Changes in the size and frequency of gully area based on soil texture in the time period studied

\begin{tabular}{|c|c|c|c|c|c|c|c|c|}
\hline \multirow{2}{*}{\multicolumn{2}{|c|}{ 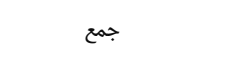 }} & \multicolumn{6}{|c|}{ مساحت آبكندى شده } & \multirow{3}{*}{ بافت خاى } \\
\hline & & \multicolumn{2}{|c|}{ IHE } & \multicolumn{2}{|c|}{ אשומו } & \multicolumn{2}{|c|}{ טמזו } & \\
\hline درصد & هكتار & درصد & هكتار & درصد & هكتار & درصد & هكتار & \\
\hline r/W & $\mid V^{4} / 94$ & $r / 91$ & $10 \cdot / 90$ & $\cdot / 4$ & $r \cdot / V \Lambda$ & .1 .9 & T/Tt & سيلتى - لومى \\
\hline $1 / 1 f$ & Q१/1९ & .194 & $F V / V \Psi$ &.$/ 1 \Lambda$ & $q / \mu r$ & $\cdot / \cdot \varphi^{\mathrm{f}}$ & $r / .9$ & لوم- سيلتى \\
\hline r/DT & (1/. & r/AF & $191 / \mathrm{rV}$ & $\cdot / \Delta \Lambda$ & $r \cdot / r$ & $\cdot / 1$ & $\Delta / \mu$ & كل \\
\hline
\end{tabular}

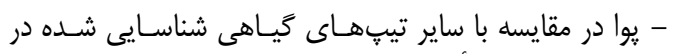

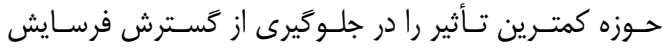

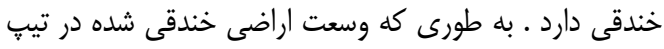

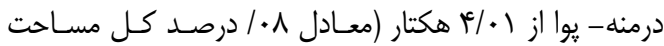

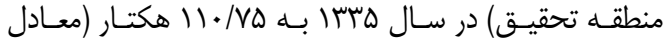

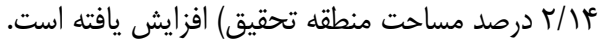

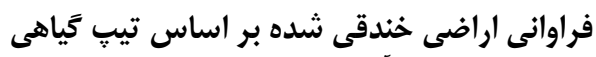

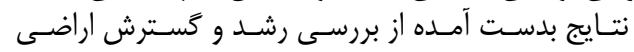

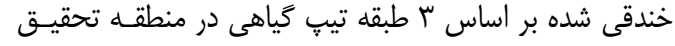

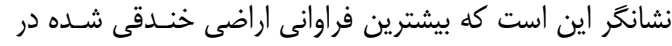

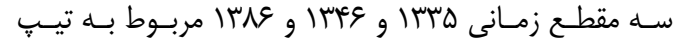

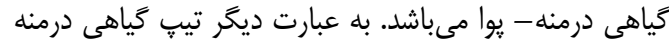

جدول • ا- تغييرات وسعت و فراوانى اراضى خندقى شده بر اساس تيّ گياهى در مقاطع زمانى مورد مطالعه Table 10. Changes in the size and frequency of gully area based on vegetation types in the time period studied

\begin{tabular}{|c|c|c|c|c|c|c|c|c|}
\hline \multirow{2}{*}{\multicolumn{2}{|c|}{ جمع }} & \multicolumn{6}{|c|}{ مساحت آبكندى شده } & \multirow{3}{*}{ تيب گياهى } \\
\hline & & \multicolumn{2}{|c|}{ IrNS } & \multicolumn{2}{|c|}{ Irfs } & \multicolumn{2}{|c|}{ DIMD } & \\
\hline درصد & هكتار & درصد & هكتار & درصد & هكتار & درصد & هكتار & \\
\hline $1 / 01$ & $V / / 19$ & $1 / \pi V$ & $V \cdot / 09$ & 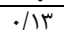 & $9 / 94$ & $.1 \cdot 1$ & $.18 \Lambda$ & كونه زراعى \\
\hline . /et & $r / \Delta \Delta$ & سז/. & $\mid V / \cdot F^{c}$ & $\cdot / \cdot 1$ & r/q. & $\cdot 1 \cdot 1$ &.$|8|$ & درمنه - علف باغ \\
\hline$r / \Delta Q$ & $\mid r F / \cdot V$ & $r / I f$ & $11 \cdot / v a$ & ./rV & $19 / 41$ & $\cdot 1 \cdot 1$ & $4 / \cdot 1$ & درمنه - يوا \\
\hline r/QT & . & r/Af & $191 / \mathrm{rV}$ & $\cdot / \Delta \mathrm{A}$ & $r \cdot /$ r &.$/ 1$ & D/ & كل \\
\hline
\end{tabular}

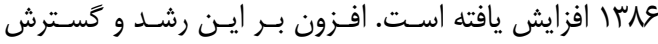

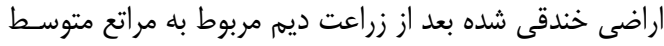

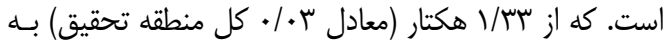

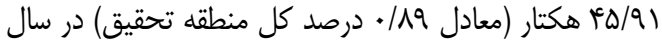

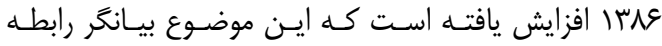

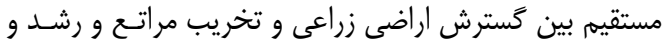
توسعه فرسايش خندقى مى باشد.
فراوانى اراضى خندقى شده بر اساس كاربرى اراضى

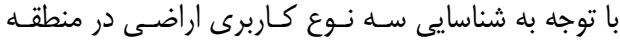

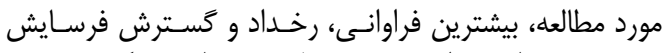

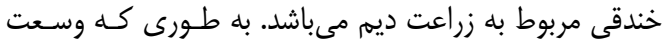

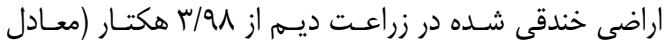

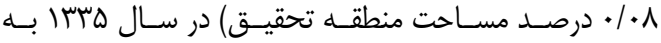

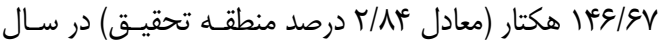


يثروهشنامه مديريت حوزه آبخيز سال هشتم/ شماره DQ / بهار و تابستان عوسا .

جدول II - تغييرات وسعت و فراوانى اراضى خندقى شده بر اساس كاربرى اراضى در مقاطع زمانى مورد مطالعه Table 11. Changes in the size and frequency of gully area based on land use in the time period studied

\begin{tabular}{|c|c|c|c|c|c|c|c|c|}
\hline \multirow{2}{*}{\multicolumn{2}{|c|}{ جمع }} & \multicolumn{6}{|c|}{ مساحت خندقى شده } & \multirow{3}{*}{ نوع كاربرى اراضى } \\
\hline & & \multicolumn{2}{|c|}{ 崔 } & \multicolumn{2}{|c|}{ ITES } & \multicolumn{2}{|c|}{ ITL } & \\
\hline درصد | (بد & هكتار & درصد & هكتار & درصد & هكتار & درصد & هكتار & \\
\hline$\Gamma / \pi \omega$ & 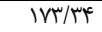 & $T / \lambda F^{2}$ & $198 / 9 \mathrm{~V}$ &.$/ 4 y^{2}$ & $r / 99$ & $\cdot 1 \cdot 1$ & $r / q \Lambda$ & زراعت ديه \\
\hline $1 / \cdot \Delta$ & $\Delta F / T V$ & .119 & $(20) / 91$ &.$/ 1 f$ & $V / \cdot F$ &.$\mu$ & سז/1 & مراتع متوسط \\
\hline.$/ 1 r$ & $8 / 1 \Lambda$ &.$/ 11$ & ৫/Vq & $.1 \cdot 1$ & •/ץq &.$/$. &.$/$. & زرا \\
\hline$r / \Delta r$ & 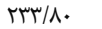 & $r / \lambda f$ & $194 / \% \mathrm{~V}$ & $\cdot / \Delta \Lambda$ & $r \cdot / r$ &.$/ 1$ & ه/T & حمع \\
\hline
\end{tabular}

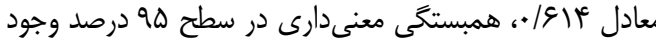

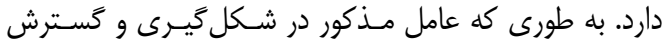
رابطه بين طبقات ارتفاعى و رشد و گَسترش فرسايش

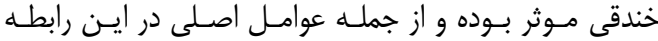
مىباشد.

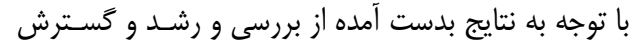

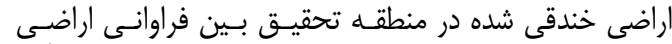

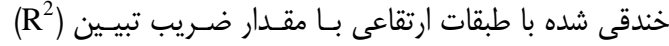

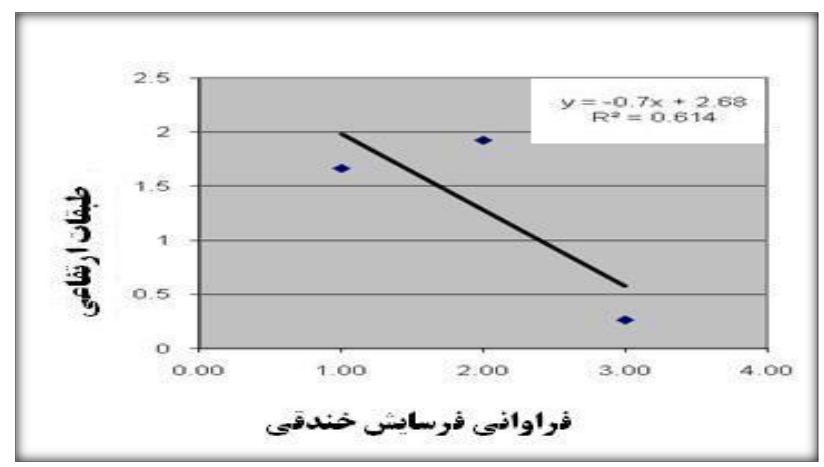

شكل צ- رابطه بين فراوانى اراضى خندقى شده با ارتفاع

Figure 6. Relation between frequencies of gully area with elevation

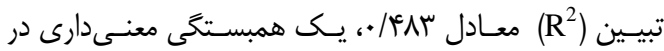

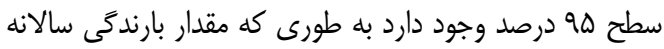

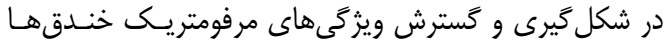

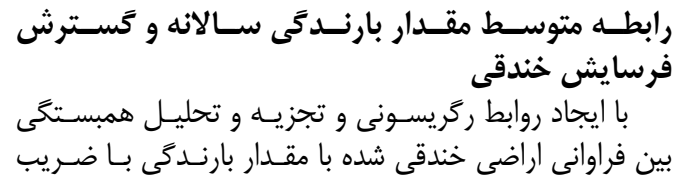
يكى از موثرترين عوامل مى باشد.

جدول rا- رابطه بين فراوانى اراضى خندقى شده با مقدار بارندگى Table 12. Relation between frequencies of gully area with amount of rainfall

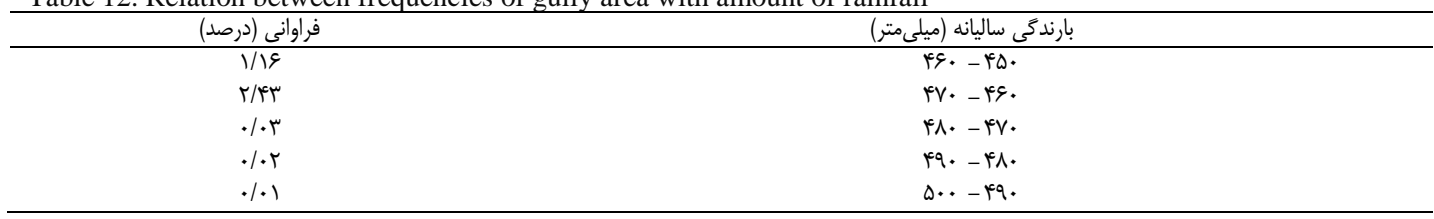




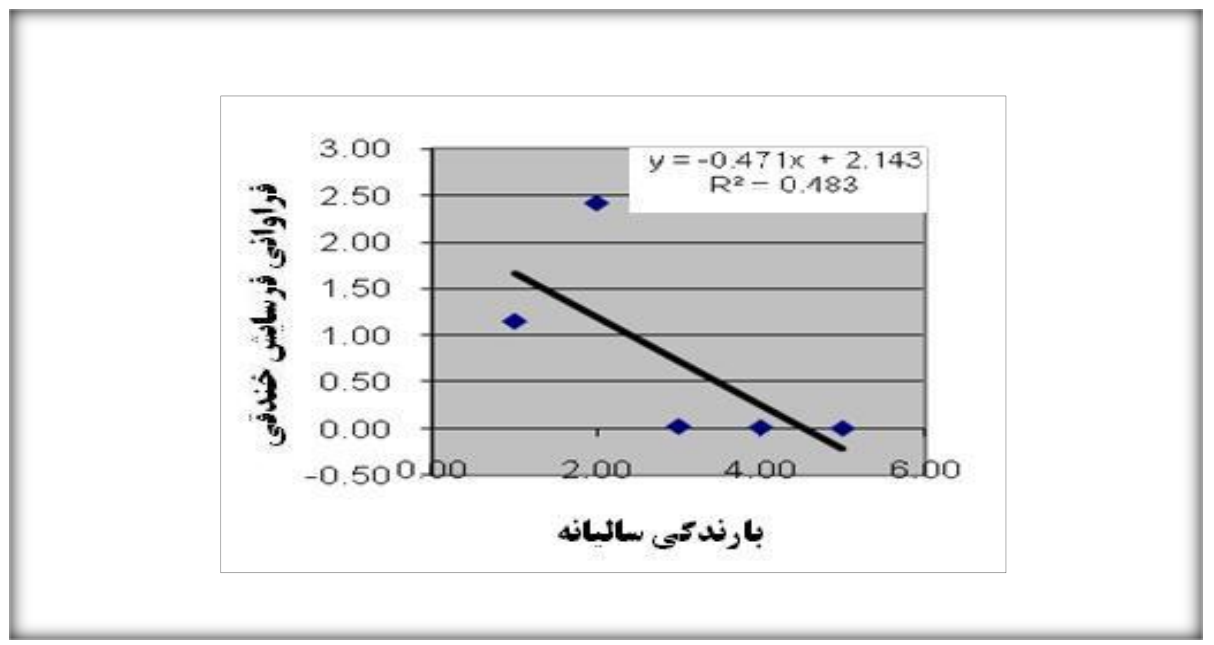

شكل V- رابطه بين فراوانى اراضى خندقى شده با ميزان بارندگى

Figure 7. Relation between frequencies of gully area with amount of rainfall

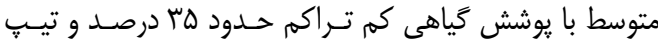

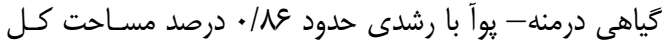

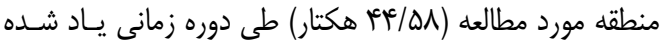
بوده است.

با شرح مجموع مطالب فوق و با توجه به تجزيه وران ور تحليل

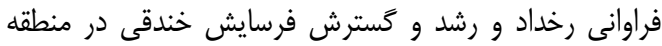

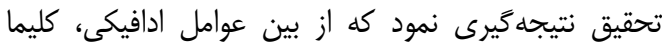

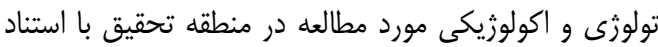

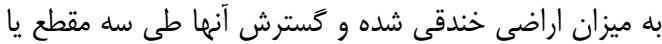

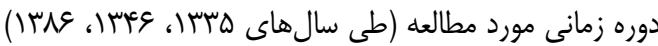

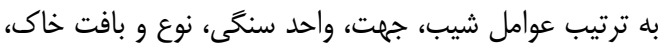

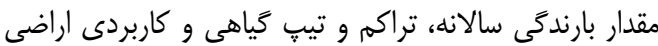

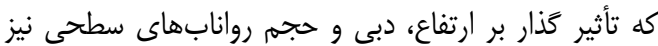

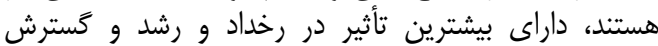

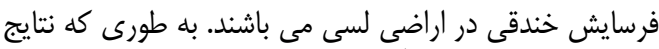

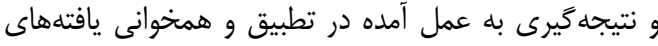

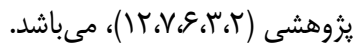

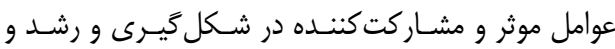

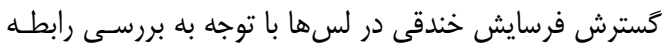

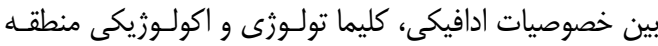

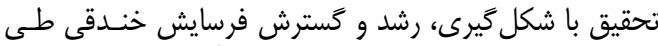

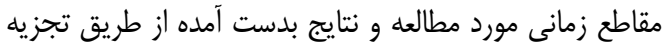

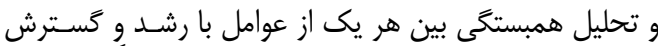

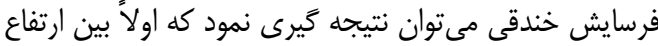

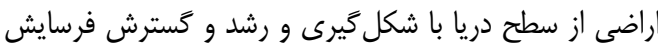

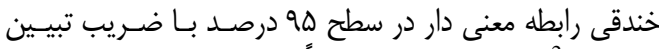

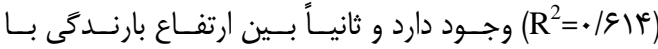

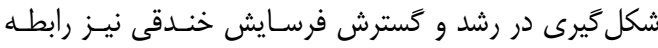

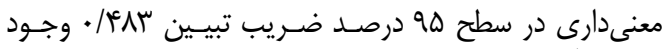

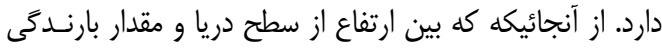

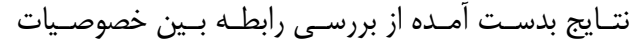

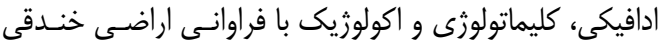

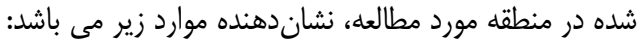

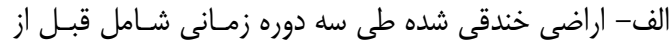

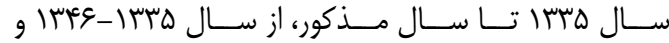

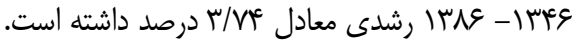

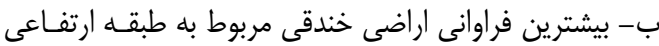

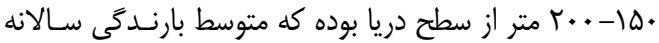

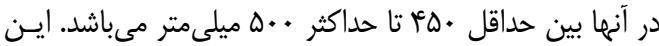

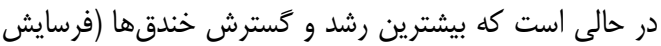

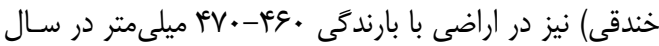

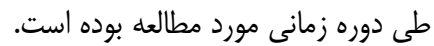

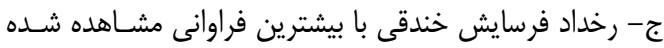

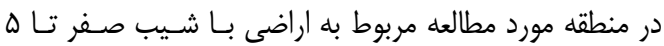

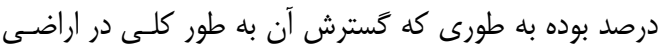

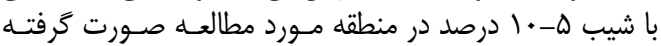

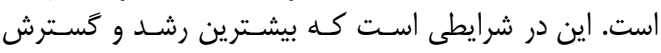

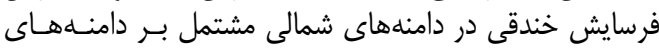

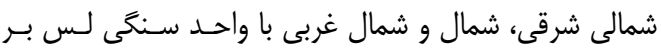

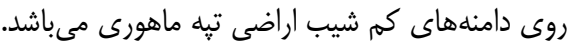

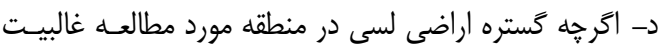

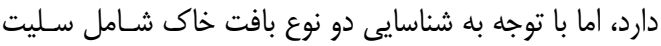

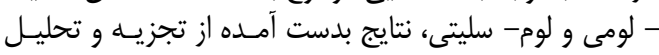

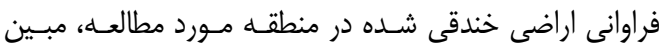

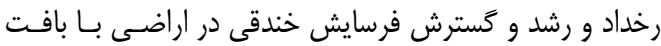

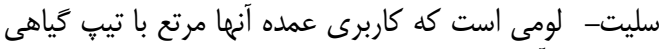

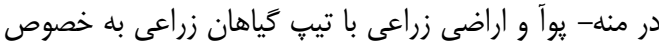

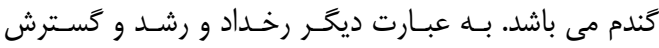

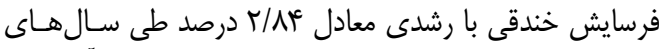

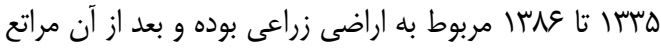




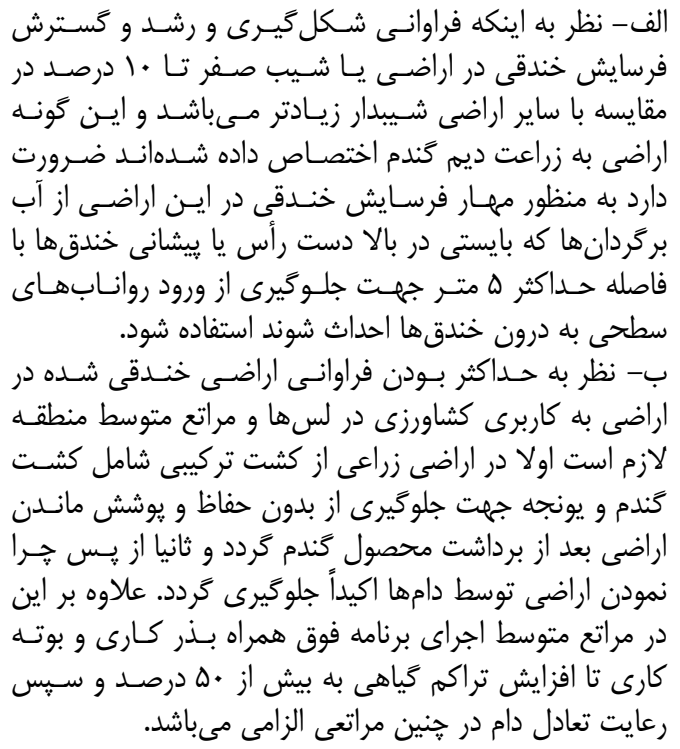

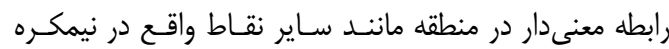

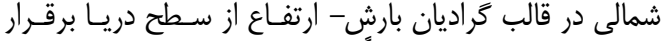

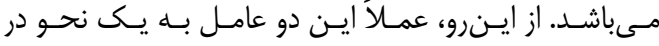

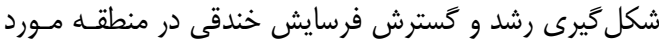

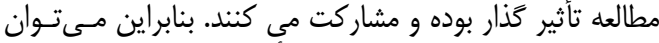

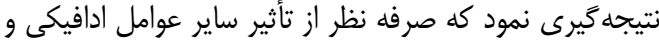

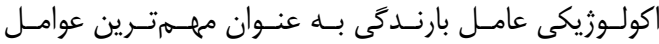

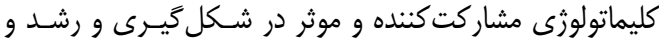

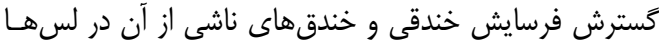

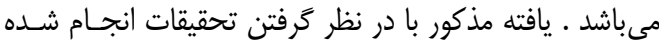

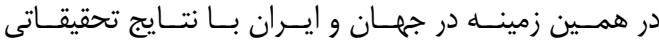

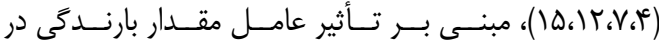

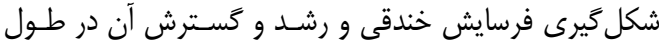

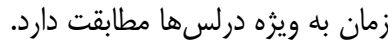

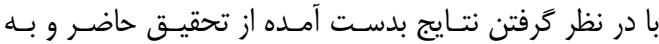

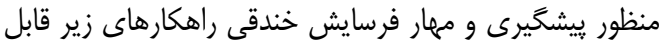
ارائه مىباشند.

1. Ahmadi, H. 1999. Functional geomorphology Second volume Tehran University, 650 pp (In Persiar

2. Amini, A. 1995. Study about loss sediment primordial and mechanism in watery district of Ghareh Tikan, M.Sc. Thesis Academy of science, Tehran University, 255 pp (In Persian).

3. Bull .I .J. M.J. Kirkby. 2002. Channel heads extension. In: Bull .L.J. and M.J. Kirkby (Eds). Druland Rivers Hydrology and geomorphology of semiarid channel Wiley chinchester, UK. pp: 33-45.

4. Dadkhah, M. 2006. Recognition the effect of some effective factors on gully erosion development in loss land (A case study Arab Ghareh Haji watery district in Golestan province). M.Sc. Thesis, Shahid Beheshti University of Tehran, 128 pp (In Persian).

5. Darvishzadeh, A. 1991. Iran geology, propagation of Nashr-e-Danesh-e-Emrooz, Dependant of Amir Kabir press and emission institute, 237 pp (In Persian).

6. Ghoddosi, J. and H.R.S. Ahmadi. 2004. A collection of articles about the first water and soil resources management conference, $12 \mathrm{pp}$ (In Persian).

7. Ghoddosi, J. 2003. Modeling gully erosion morphology and its danger expansion (A Case Study Zanjan-rood watery district). Academy of Natural Science, Tehran University, $35 \mathrm{pp}$ (In Persian).

8. Khajeh, M. Ghayomian, J and Sadat Feyznia. 2005. Recognition of the effect of physical and chemical and climate factors on production of the sediment caused by surface loss soil erosion. (A case study Golestan province) Research and structure serial, 66: 12-24 (In Persian).

9. Manafzadehnia, N. 2007. Accuracy assess in two models of hydrolophysical estimation and EPM (A case study Taleghan watery district). M.Sc. Thesis, Academy of agricultural and natural science of Azad University, a unit of Tehran science and research, 135 pp (In Persian).

10. Poeson, J., L. Vanderkerchove, J. Nachtergaele, D. Dostwoud, G.Wijenes, G. Verstraeten and B. Van Wesemeal. 2002. Gully erosion in dry land environment .In: Bull and Kirkby, U K. 250 pp.

11. Pimentel, D., J. Allen and A. Beers. 1997 .World agricultural and soil erosion .Bioscience, 37: 277 283.

12. Poeson, J. and G. Govers.1990. Gully erosion in the loam belt at Belgium Typology and control measures Seal John wiley and sons, pp: 513-530.

13. Refahi, H.Gh. 2003. Water erosion and control of it Tehran University press.Shahini, Gh. The role of herbal coverage on control of gully erosion a collection of the third national conference of erosion and sediment articles, pp: 341-346 (In Persian).

14. Shahrivar, A. 1997. Study about the effective factors on gully erosion and offering a model in Soogh region in Dehdasht Township. M.Sc. Thesis. Academy of natural science Tehran University, $124 \mathrm{pp}$ (In Persian).

15. Sayyadi, M.G. 2006. Study about the effect of some effective factors on gully erosion development in loss land. (A case study: Agh Imam Kachik watery district in Golestan province M.Sc. Thesis gorgan agricultural science and Natural Resource University, 185 pp (In Persian). 


\title{
Investigation of the Effect of Earth Environmental Factors on Initiation and Expansion of Gully Erosion by using Geographical Information System (Case Study in Temer Ghareh Ghozi, Kalaleh, Golestan Province)
}

\begin{tabular}{c} 
Nasir Khojeh', Jamal Ghoddosi $\mathbf{~ a n d ~ R o h o l l a h ~ E s m a i l i ~}^{\mathbf{3}}$ \\
\hline 1- Graduated M.Sc. Student, Azad Islamic University of Tehran \\
2- Associate Professor, Shahid Beheshti University. \\
3- PhD Student, Faculty of Natural Resources, Lorestan University \\
(Corresponding author: esmailirohollah598@ gmail.com) \\
Received: March 17, 2012 $\quad$ Accepted: May 17, 2014 \\
\hline \hline
\end{tabular}

\begin{abstract}
According to the importance of loss areas, which have embarrassed a wide region of Golestan province and its important role in formation of the sediment of Gorgan river, more accurate recognition of types of loss erosion seems essential in order to providing necessary function for erosion and sediment problems in them, specially gully erosion. So, in this study we are going to providing regression model through investigation of effective earth environmental factors on gully erosion to identify gully initiation mechanism on loss land. For this, locational situation of the gully (Temer Ghareh Ghozi region) was identified after recognizing airy photos in the scale of 1:20000 and basic study as climate, geology, soil, herbal coverage, land function, and topography began after providing unit topography by using geographical information system. In order to control the effect of herbal coverage on initiation of gully erosion, we work to remove density of herbal coverage by $1 * 1$ square meter plots. Finally, a proper regression model was offered to develop gully erosion, after recognition and computation the relationship between environmental earth factors with initiation, growth and development of gully erosion through multi-variable analysis by using SPSS. The result shows that earth environmental factors such as height, slope, and aspect, height of hillside, annual rainfall, stone units, land type and density of herbal coverage have an effective role in initiation and expansion of gully erosion in loss land.
\end{abstract}

Keywords: Earth environmental factors, GIS, Gully erosion, Gully initiation mechanism, Loss, Regression model 